\title{
Synergistic Effects of Age on Patterns of White and Gray Matter Volume across Childhood and Adolescence ${ }^{1,2,3}$
}

\author{
Signe Bray ${ }^{1,2,3,4}$, Mark Krongold,, ${ }^{3,4,5}$ Cassandra Cooper, ${ }^{3,4}$ and Catherine Lebel ${ }^{1,2,3,4}$
}

\section{DOI:http://dx.doi.org/10.1523/ENEURO.0003-15.2015}

\begin{abstract}
${ }^{1}$ Department of Radiology, Cumming School of Medicine, University of Calgary, Calgary, Alberta, Canada T2N 1N4, ${ }^{2}$ Department of Pediatrics, Cumming School of Medicine, University of Calgary, Calgary, Alberta, Canada T2N 1N4, ${ }^{3}$ Child and Adolescent Imaging Research Program, Alberta Children's Hospital, Calgary, Alberta, Canada T3B 6A8,

${ }^{4}$ Alberta Children's Hospital Research Institute, Calgary, Alberta, Canada T3B 6A8, and ${ }^{5}$ Biomedical Engineering Graduate Program, University of Calgary, Calgary, Alberta, Canada T2N 1N4
\end{abstract}

\begin{abstract}
The human brain develops with a nonlinear contraction of gray matter across late childhood and adolescence with a concomitant increase in white matter volume. Across the adult population, properties of cortical gray matter covary within networks that may represent organizational units for development and degeneration. Although gray matter covariance may be strongest within structurally connected networks, the relationship to volume changes in white matter remains poorly characterized. In the present study we examined age-related trends in white and gray matter volume using T1-weighted MR images from 360 human participants from the NIH MRI study of Normal Brain Development. Images were processed through a voxel-based morphometry pipeline. Linear effects of age on white and gray matter volume were modeled within four age bins, spanning 4-18 years, each including 90 participants ( 45 male). White and gray matter age-slope maps were separately entered into $k$-means clustering to identify regions with similar age-related variability across the four age bins. Four white matter clusters were identified, each with a dominant direction of underlying fibers: anterior-posterior, left-right, and two clusters with superior-inferior directions. Corresponding, spatially proximal, gray matter clusters encompassed largely cerebellar, fronto-insular, posterior, and sensorimotor regions, respectively. Pairs of gray and white matter clusters followed parallel slope trajectories, with white matter changes generally positive from 8 years onward (indicating volume increases) and gray matter negative (decreases). As developmental disorders likely target networks rather than individual regions, characterizing typical coordination of white and gray matter development can provide a normative benchmark for understanding atypical development.
\end{abstract}

Key words: cortex; MRI; structural covariance network; white matter

\section{Significance Statement}

The structure of the brain changes across late childhood and adolescence: gray matter volume decreases and white matter volume increases. Gray matter changes occur within networks that may be targets for neurodegenerative, developmental, and psychiatric disorders. This study demonstrates that changes in white matter volume are also coordinated across regions, and that changes in these clusters parallel corresponding gray matter clusters. While gray matter clusters show a posterior to anterior organization, we observe here that white matter volume groups into regions with similar fiber orientation. This work adds to our understanding of typical gray and white matter development, which ultimately can help understand how the brain may be developing abnormally in neurodevelopmental disorders. 


\section{Introduction}

As the brain develops across late childhood and adolescence, a pattern of white matter expansion (Giedd et al., 1999; Paus et al., 1999; Sowell et al., 2002; Taki et al., 2013) and gray matter contraction (Sowell et al., 2003, 2004; Gogtay et al., 2004; Shaw et al., 2008) has been observed. These co-occurring phenomena are widely considered to be the product of developmental exuberance (Innocenti and Price, 2005), through which an overproduction of connections is followed by a selection process. White matter volume expansion is thought to reflect both an increase in myelination and axonal diameter (Yakovlev and Lecours, 1967; Benes, 1989; Benes et al., 1994; Rademacher et al., 1999; Paus, 2010). Observed patterns of gray matter thinning may reflect synaptic pruning (Huttenlocher, 1979), changes in size and number of glia or size of neurons (Elgeti et al., 1976; Drevets et al., 1998; Cotter et al., 2002), vasculature (Vaidya et al., 2007), or changes in myelination of superficial white matter (Sowell et al., 2004; Shaw et al., 2008, but see Wu et al., 2014).

Distributed cortical regions show correlated anatomical features across the population (Mechelli et al., 2005; Lerch et al., 2006; Chen et al., 2008; Tijms et al., 2012; Alexander-Bloch et al., 2013b; Evans, 2013) in networks similar to those defined by resting state functional connectivity (Segall et al., 2012; Alexander-Bloch et al., 2013b) and white matter tractography (Gong et al., 2012). These findings have been extended to describe coordinated cortical development across childhood and adolescence (Zielinski et al., 2010; Raznahan et al., 2011b; Alexander-Bloch et al., 2013b, 2014; Khundrakpam et al., 2013). The importance of these findings is underscored by the suggestion that neurodegenerative, psychiatric, and

Received January 11, 2015; accepted April 30, 2015; First published July 01, 2015.

${ }^{1}$ C.L.'s spouse is an employee of General Electric Healthcare.

${ }^{2}$ Author Contributions: S.B. designed research, analyzed data and wrote the paper; M.K. and C.C. analyzed data and wrote the paper; C.L. analyzed data and wrote the paper.

${ }^{3}$ M.K. was supported by an NSERC CGS-M and C.C. was supported by an NSERC USRA. This work was supported by an NSERC Discovery Grant (S.B.), and the Alberta Children's Hospital Foundation. Data used in the preparation of this article were obtained from the Pediatric MRI Data Repository created by the NIH MRI Study of Normal Brain Development. This is a multisite, longitudinal study of typically developing children, from ages newborn through young adulthood, conducted by the Brain Development Cooperative Group and supported by the National Institute of Child Health and Human Development, the National Institute on Drug Abuse, the National Institute of Mental Health, and the National Institute of Neurological Disorders and Stroke (N01-HD023343; N01-MH9-0002; and N01-NS-9-2314, N01-NS-9-2315, N01-NS-92316, N01-NS-9-2317, N01-NS-9-2319, and N01-NS-9-2320). A listing of the participating sites and a complete listing of the study investigators can be found at http://www.bic.mni.mcgill.ca/nihpd/info/participating_centers.html. We thank the families who gave their time to participate in this study and the Brain Development Cooperative Group for making these data available.

Correspondence should be addressed to Signe Bray, Alberta Children's Hospital, 2888 Shaganappi Trail NW, A0-401, Calgary, Alberta, T3B 6A8, Canada. E-mail: slbray@ucalgary.ca.

DOI:http://dx.doi.org/10.1523/ENEURO.0003-15.2015

Copyright (C) 2015 Bray et al.

This is an open-access article distributed under the terms of the Creative Commons Attribution 4.0 International, which permits unrestricted use, distribution and reproduction in any medium provided that the original work is properly attributed. neurodevelopmental disorders may target cortical networks rather than specific regions (Seeley et al., 2009; Raznahan et al., 2010; Reid et al., 2010; Zielinski et al., 2012; Alexander-Bloch et al., 2014).

White matter tracts also show developmental changes in structural properties (Barnea-Goraly et al., 2005; Ben Bashat et al., 2005; Giorgio et al., 2008; Lebel and Beaulieu, 2011). Fractional anisotropy (FA), a measure of coherent fiber orientation linked to myelination and axon packing (Beaulieu, 2002), increases in most tracts (Barnea-Goraly et al., 2005; Lebel et al., 2008) and peaks in early adulthood before declining (Lebel et al., 2012). Mean diffusivity (MD), a measure reflecting water content and density, shows an opposite pattern, declining across adolescence and increasing in adulthood (Lebel and Beaulieu, 2011). The volume of white matter tracts also typically increases across childhood, though the relationship between tract-volume and microstructural parameters is complex (Lebel and Beaulieu, 2011).

Although gray matter developmental networks are increasingly well characterized, the relationship between white matter structural changes and network-level gray matter development remains unclear. In the present study, we tested the hypothesis that clusters of white matter regions would show coordinated volume development, parallel to gray matter clusters. That is, clusters of white matter regions showing coordinated variability with age (e.g., volume expansion) would be inversely associated with changes in gray matter volume (e.g., contraction), in related regions, across childhood and adolescence.

\section{Materials and Methods}

\section{Participants and neuroimaging data}

Neuroimaging data were obtained from the $\mathrm{NIH} \mathrm{MRI}$ study of Normal Brain Development's Pediatric MRI Data Repository (Evans and Brain Development Cooperative Group, 2006). The cohort includes 433 typically developing participants, male and female, aged 4:6-18:3 years. All subjects are purported to be normal and healthy, e.g., no history of brain disease or trauma, with an $I Q>70$. Analyses reported here used T1-weighted images collected on 1.5 T MRI scanners (GE or Siemens) at six sites (Boston Children's Hospital; Cincinnati Children's Hospital Medical Center; University of Texas Houston Medical School; Neuropsychiatric Institute and Hospital, UCLA; Children's Hospital of Philadelphia; and Washington University, St. Louis). Parameters for whole-brain T1weighted acquisitions were standardized across sites: 3D RF-spoiled gradient echo, TR $=22-25 \mathrm{~ms}$, TE $=10-11$ $\mathrm{ms}$, sagittal acquisition, FOV $=$ AP 256, LR 160-180. Resolution was typically $1 \mathrm{~mm}^{3}$; however, on GE scanners on which thickness was increased up to $1.5 \mathrm{~mm}$ and in some participants resolution was decreased to $3 \mathrm{~mm}^{3}$ to enable more rapid imaging. For our sample we generated four evenly sized groups of participants (90) with an equal number of males and females (45), for a total sample including 360 high-quality scans. Age groups were 4-8, $8-10.5,10.5-13.5$, and 13.5-18.5 years; detailed information about participants is provided in Table 1. 
Table 1. Participant demographics

\begin{tabular}{llll}
\hline & Group 1 & Group 2 & Group 3 \\
Mean & $6.47(0.81)$ & $9.16(0.76)$ & $12.04(0.84)$ \\
Age range (years) & $4.80-7.85$ & $8.02-10.47$ & $10.68-13.50$ \\
Mean IQ (SD) & $110.9(16.0)$ & $112.5(12.9)$ & $112.1(10.7)$ \\
IQ range & $79-156$ & $77-160$ & $84-131$ \\
Handedness R:L & $83: 7$ & $80: 10$ & $80: 10$ \\
Gender M:F & $45: 45$ & $45: 45$ & $45: 45$ \\
Mean adjusted income & $71.1(32.5)$ & $70.0(30.6)$ & $70.1(32.0)$ \\
Thousands (SD) & & & $71.03(1.27)$ \\
\end{tabular}

\section{VBM processing}

T1-weighted MRI scans were processed through a voxel-based morphometry (VBM) pipeline in SPM12b. Steps included segmentation and normalization using a custom template generated with the DARTEL Toolbox (Ashburner, 2007). Normalized gray and white matter segmented images were modulated to "preserve amounts" and smoothed using an $8 \mathrm{~mm}$ Gaussian kernel. All segmentations were visually inspected prior to analysis. VBM tools were also used to identify potential outliers by calculating the squared distance to sample mean in each age bin; no outliers were identified in this step.

\section{Linear age models}

As developmental changes in gray matter volume across childhood and adolescence are known to be nonlinear (Gogtay et al., 2004; Shaw et al., 2008; Raznahan et al., 2011a), our sample was divided into four age bins similar to Zielinski et al. (2010) and Khundrakpam et al. (2013). Two general linear models were estimated in each age group, modeling a linear effect of mean-centered age on gray and white matter volume separately. Models included effects of gender, site (one regressor per site), and a linear effect of image resolution. Explicit masks were used to spatially constrain the analyses; gray and white matter masks were created using the Masking Toolbox in SPM12b (Ridgway et al., 2009) and constrained to probabilities $>0.4$ to ensure that there was no overlap in gray and white matter masks. Neither proportional scaling nor total brain volume regression were used in the main models reported here. However, both methods were tested in additional analyses, as described below.

\section{Clustering based on gray and white matter age slope}

For each tissue type (white and gray matter), parameter estimates for the effect of age in each of the four age bins were obtained for each voxel. All parameter estimates ( $\beta$-values) were entered into a pair of matrices, one gray and one white matter, in which each row corresponded to a voxel and each column corresponded to an age bin. Analyses were performed on all voxels independent of the significance of age effects, that is, voxel-level significance of age effects was not assessed as part of this study. Matrices were entered into $k$-means clustering in MAT$L A B$ to identify clusters of voxels with similar age slopes across these developmental stages. Clustering was seeded with random centers and repeated 10 times; 2-10 cluster solutions were tested, and peak silhouette values
(Kaufman and Rousseeuw, 1990) were used to identify the optimal clustering solution for each tissue class.

\section{Directional bias in white matter clusters}

Visual inspection of white matter clusters indicated a potential directional bias. To test this, white matter clusters were compared against directional maps from the ICBM-DTI-81 Atlas (Mori et al., 2008) to determine the primary direction of white matter fibers in each cluster. This atlas includes estimated eigenvalues for eigenvectors corresponding to three principal directions ( $x$ : rightleft, $y$ : anterior-posterior, $z$ : superior-inferior). To determine whether voxels assigned to each white matter cluster had a preferred direction, the three eigenvalue maps were masked by each white matter cluster. For each cluster the subset of voxels with a dominant orientation along one of these principal directions was obtained by thresholding to include only voxels for which at least one eigenvalue was $\geq 0.4$. We then calculated the proportion of voxels for which the maximum eigenvalue was in each principal direction.

\section{Effects of site and resolution on VBM segmentation}

As previous studies have shown that VBM segmentations may be affected by data collection site and acquisition parameters (Pardoe et al., 2008; Pereira et al., 2008; Focke et al., 2011; Takao et al., 2013), additional analyses were run to investigate effects of data collection site and image resolution. We note that participant age did not significantly vary by site $\left(F_{(1,360)}=0.02, p=0.88\right)$. Resolution did show a significant negative trend with age as the youngest participants were more likely to have larger voxel size $\left(F_{(1,360)}=12.6, p<0.001\right)$. However, resolution did not significantly vary with age in individual age bins, though a trend remained in the youngest bin $(p=0.051$, $p=0.73, p=0.60, p=0.22$ ). To determine which regions may be affected by these parameters, models were run for gray and white matter volume separately including all 360 participants; effects of age, resolution, gender, and site were modeled (one column per site). $F$-contrasts were used to identify regions showing linear effects of resolution on gray and white matter volume, and nonlinear effects of site. We then compared clustering results, for models that included these covariates with a set of models that did not include site and resolution covariates, to assess effects of these parameters on clustering results. 

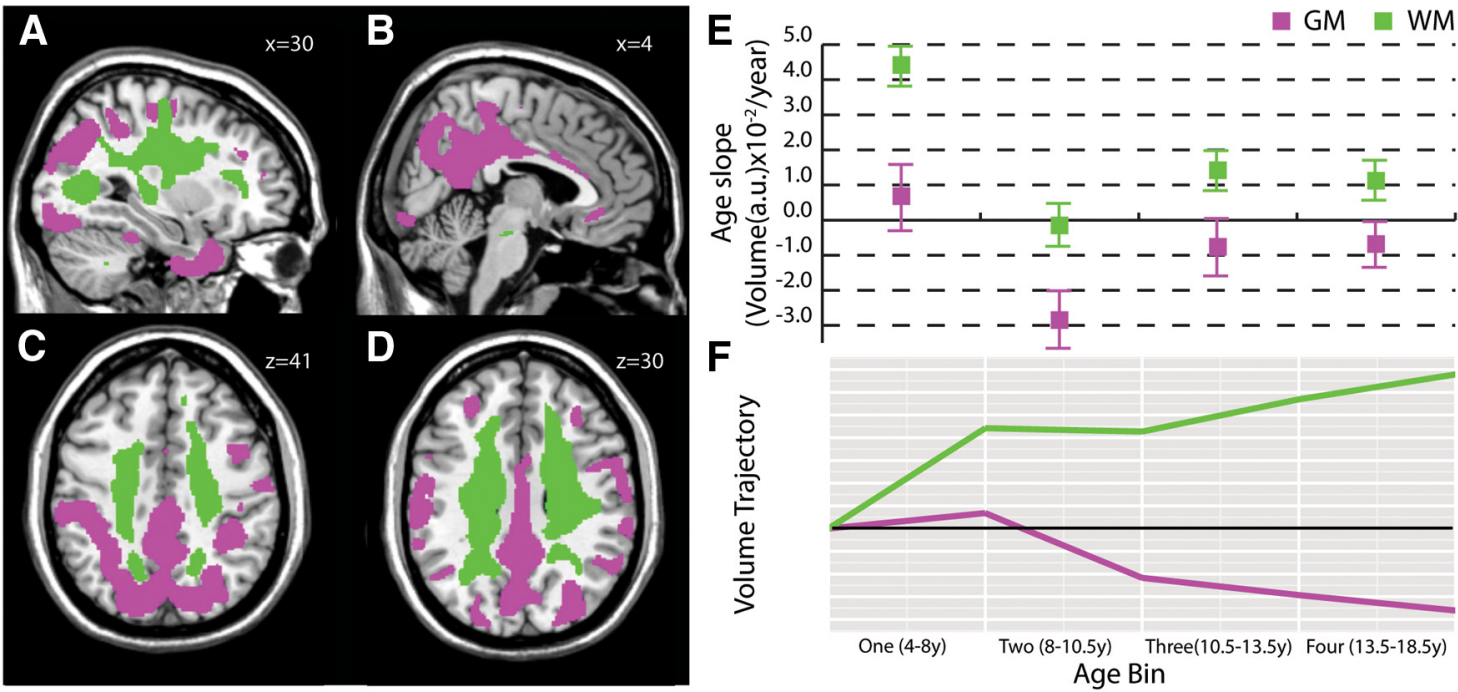

Figure 1. Superior corona radiata/posterior gray matter clusters. This white matter cluster included deep white matter of the superior longitudinal fasciculus, superior corona radiata, and body of the corpus callosum $(\boldsymbol{A}, \boldsymbol{C}, \boldsymbol{D})$ and included mostly $(68 \%$ of voxels) superior-inferior-oriented voxels. The corresponding gray matter cluster included primarily posterior cortical regions $(\boldsymbol{A}-\boldsymbol{D})$, including precuneus $(\boldsymbol{B})$ and bilateral intraparietal sulcus $(\boldsymbol{C})$. Mean gray and white matter slopes for the cluster with SDs $(\boldsymbol{E})$ and a graphical illustration of volume trajectories $(\boldsymbol{F})$ are shown for all four age bins. GM, gray matter; WM, white matter.

\section{Effects of modeling total gray and white matter volume}

Many VBM studies model effects of total tissue volume, enabling the identification of regions that discriminate between groups after differences in total volume are accounted for (Peelle et al., 2012). Significance of regional effects of age is sensitive to the choice of model (Peelle et al., 2012). For the main analysis here, we chose not to account for total gray and white matter volume, as our goal was simply to model age trends and not to identify regions where age effects were greater than the mean. However, to investigate differences in our results when accounting for total volume, two additional models were run, using proportional scaling by total tissue volume and including total tissue volume as a nuisance covariate.

\section{Effects of age on image contrast}

T1-image contrast is known to increase over the first few years of childhood (Paus et al., 2001; Shi et al., 2010). Although the population assessed here was older (i.e., the youngest participant was 4.8 years), systematic effects of image contrast may nonetheless contribute to variable quality of gray/white segmentation, and these effects may vary between brain regions. To assess effects of image contrast as a function of age, bilateral masks covering frontal, temporal, parietal, and occipital gray and white matter regions were generated using the Wake Forest Pick Atlas tool (Maldjian et al., 2003) and the TD-ICBM152 atlas (Mazziotta et al., 2001). These masks were warped into each participant's native space and used to extract regional gray and white matter values. Contrast was calculated in each subject and each region as follows: $C=$ (white matter intensity-gray matter intensity)/ gray matter intensity. We then assessed effects of age and site on contrast across the sample and within each age bin.

\section{Results}

White matter clusters ${ }^{a}$ showed a peak silhouette value at the four-cluster solution and gray matter clusters ${ }^{b}$ at the two-cluster solution (this solution divided cerebral cortex from cerebellum). As the goal of this study was to identify clusters of white matter regions with coordinated developmental patterns, in relation to gray matter clusters, both gray and white matter was divided into four clusters, which were subsequently paired based on adjacency of regions (Figs. 1-4). Gray and white matter structures were identified through visual inspection and comparison to gray and white matter atlases (TzourioMazoyer et al., 2002; Oishi et al., 2011).

\section{Superior corona radiata white matter/precuneus and} intraparietal sulcus (posterior) gray matter

One white matter cluster included the superior longitudinal fasciculus, superior corona radiata, and body of the corpus callosum (Fig. $1 A, C, D$ ), as well as a region along the posterior thalamic radiation (Fig. 1C). White matter voxels were predominantly (68\%; Fig. 5) superior-inferior in orientation (Fig. 5). The most spatially similar gray matter cluster included primarily posterior cortical regions (Fig. $1 A-D$ ) such as the precuneus (Fig. 1B) and bilateral intraparietal sulcus (Fig. 1C). This cluster also included anterior temporal cortex (Fig. 1A) and smaller bilateral regions of posterior middle frontal gyrus (Fig. 1D). The gray matter cluster was characterized by a steep negative slope in the 8-10.5 year age bin and more positive slopes in other age groups; white matter age slopes followed a similar trend, though slopes were generally positive (indicating increasing volume with age; Fig. $1 E-F)$. 

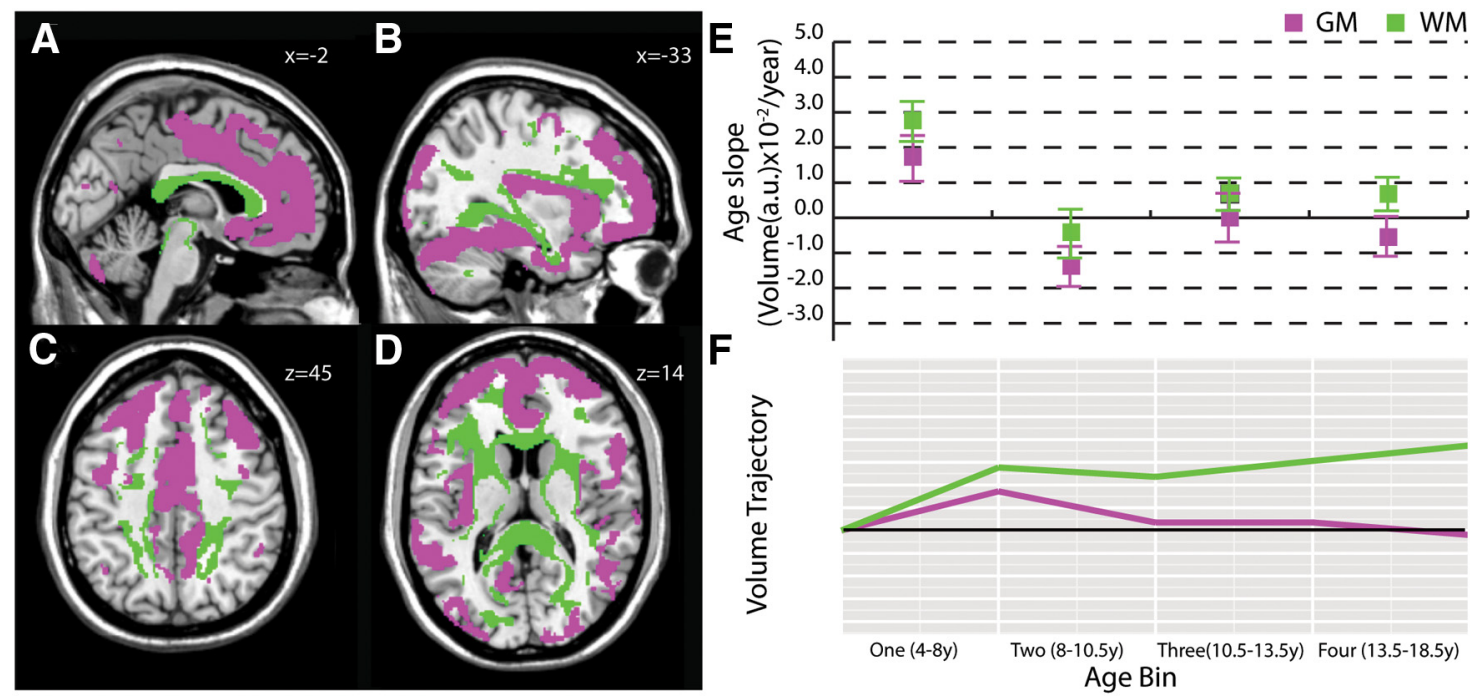

Figure 2. Medial callosal white matter/anterior gray matter clusters. This white matter cluster included medial corpus callosum $(\boldsymbol{A})$, anterior internal capsule $(\boldsymbol{D})$, and superior parietal lobule white matter $(\boldsymbol{C})$ and was primarily ordered left-right $(70 \%)$. The corresponding gray matter cluster included anterior cingulate and medial prefrontal cortex $(\boldsymbol{A}, \boldsymbol{B}, \boldsymbol{C})$ and insular $(\boldsymbol{B}, \boldsymbol{D})$ and temporal regions $(\boldsymbol{B})$. Mean gray and white matter slopes for the cluster with SDs $(\boldsymbol{E})$ and a graphical illustration of volume trajectories $(\boldsymbol{F})$ are shown for all four age bins. GM, gray matter; WM, white matter.

\section{Medial corpus callosum white matter/anterior cingulate, prefrontal cortex, and insula (anterior) gray matter}

A second white matter cluster (Fig. 2) included medial corpus callosum (Fig. 2A), anterior internal capsule (Fig. $2 D$ ), superior parietal lobule white matter (Fig. 2C), posterior thalamic radiation and retrolenticular portion of the internal capsule (Fig. 2D), and inferior frontal gyrus white matter (Fig. 2B). White matter voxels were mostly leftright oriented (70\%; Fig. 5). The corresponding gray matter cluster included anterior cingulate and medial prefrontal cortex (Fig. 2A-C) and insular (Fig. 2B,D) and temporal regions (Fig. 2B). Gray matter age slopes (Fig. $2 E, F)$ indicated the greatest volume decreases in the 8-10.5 year age bin, though slopes in all age bins were more moderate than in the posterior cluster (Fig. 1E,F). White matter slopes paralleled gray matter, but were generally positive, except for slight volume decreases in the 8-10.5 year age bin (Fig. 2E,F).

\section{Occipital, parietal, and prefrontal white matter/visual and motor gray matter}

A third white matter cluster (Fig. 3) included superior cerebellar peduncle (Fig. $3 A$ ), occipital and superior parietal white matter (Fig. $3 B$ ), superior frontal gyrus white matter (Fig. 3C,D), posterior internal capsule (Fig. 3C), posterior thalamic radiation (Fig. 3B,C), and precentral gyrus white matter (Fig. $3 D$ ). This white matter cluster showed a strong superior-inferior orientation (74\%; Fig. 5). The corresponding gray matter cluster involved cuneus (Fig. $3 A-C$ ), motor (Fig. $3 D$ ), superior parietal (Fig. $3 B$ ), and lateral prefrontal (Fig. $3 C$ ) regions. Among the identified gray matter clusters, this set of regions showed the most moderate slopes-slightly positive in the youngest age bin and relatively stable across the 8-18.5 year age range
(Fig. 3E,F). White matter slope trajectories, again, followed a similar trend to gray matter, with a moderate but consistently positive slope from ages 8-18.5 years (Fig. $3 E, F)$.

\section{Cerebellar peduncles/cerebellum}

A fourth pair of gray and white matter clusters captured the cerebellum and cerebellar peduncles (Fig. 4). The white matter cluster included bilateral cerebellar peduncles (Fig. 4A) and portions of the superior longitudinal fasciculus (Fig. 4C); voxels were mainly anterior-posterior oriented (58\%; Fig. 5). The gray matter cluster included bilateral cerebellum (Fig. 4A), but also caudate (Fig. 4B) and dorsomedial prefrontal cortex (Fig. 4D). For both gray and white matter, the slopes for this cluster were generally positive; white matter slope was slightly negative in the 8-10.5 year age bin and gray matter slopes became slightly negative in the 14-18.5 year age bin (Fig. 4E,F).

\section{Effects of data collection site and resolution}

Previous studies have noted that VBM estimates of gray and white matter volume are sensitive to differences in MR scanner and image resolution (Pardoe et al., 2008; Pereira et al., 2008; Focke et al., 2011; Takao et al., 2013). As the present study made use of a multisite dataset, additional analyses were run to estimate potential impact of these factors on our results. A general linear model was estimated using the entire sample of 360 participants, including a linear effect of resolution and separate regressors modeling effects of each site. F-contrasts were used to identify regions sensitive to these effects. Results of $F$-contrasts for site are shown in Figure 6, $a$ and $b$, thresholded at $p<0.001$ uncorrected, for gray and white matter, respectively. We observe significant effects of site around the posterior putamen, orbitofrontal, inferior temporal, 

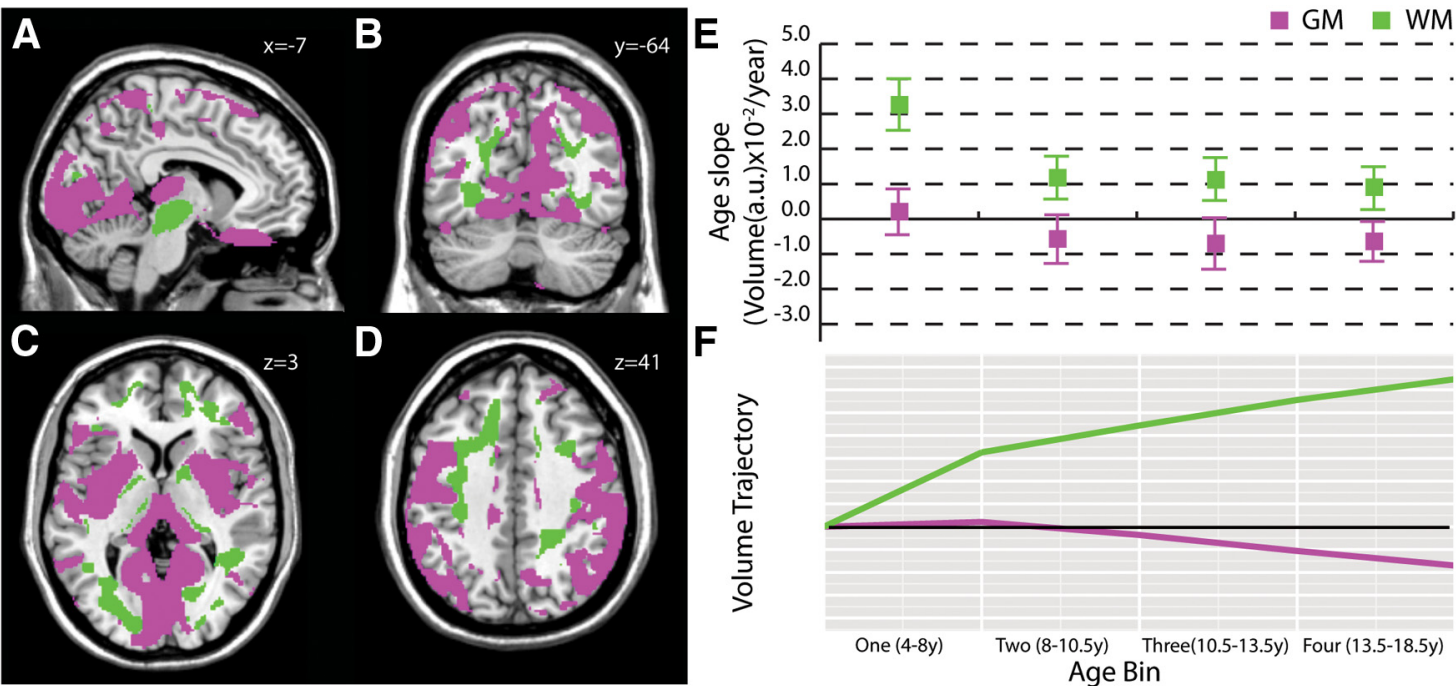

Figure 3. Frontal and occipital white matter/visuomotor gray matter. This white matter cluster included mostly superior-inferiororiented voxels $(74 \%)$ in superior cerebellar peduncle $(\boldsymbol{A})$, occipital and superior parietal $(\boldsymbol{B})$ and superior frontal gyrus white matter $(\boldsymbol{C}, \boldsymbol{D})$, posterior thalamic radiation $(\boldsymbol{B}, \boldsymbol{C})$, and precentral gyrus white matter $(\boldsymbol{D})$. The corresponding gray matter cluster recruited cuneus $(\boldsymbol{A}, \boldsymbol{B}, \boldsymbol{C})$, motor $(\boldsymbol{D})$, superior parietal $(\boldsymbol{B})$, and lateral prefrontal $(\boldsymbol{C})$ regions. Mean gray and white matter slopes for the cluster with SDs $(\boldsymbol{E})$ and a graphical illustration of volume trajectories $(\boldsymbol{F})$ are shown for all four age bins.

and peripheral gray matter in Figure 6a. Significant effects on white matter volume were most prominent around the internal capsule (Fig. 6b). Results of $F$-contrasts for resolution are shown in Figure 6, $c$ and $d$, thresholded at $p<$ 0.001 uncorrected, for gray and white matter, respectively. Affected gray matter regions were similarly concentrated around the posterior putamen and insula and occipital and dorsal prefrontal regions (Fig. 6c). For white matter, similar to effects of site, effects of resolution were largely concentrated around the internal capsule (Fig. 6d).
We next compared clustering results for age $\beta$-values from models that did and did not include effects of site and resolution. These results are shown in Figure 6, e and $f$. We note that clustering results were largely similar between these two models. Figure $6, g$ and $h$, shows gray and white matter clusters obtained from these two models overlaid; regions of overlap are shown in purple. The only regions where cluster assignment substantially differed were around the putamen and internal capsule. Overall these results suggest that effects of site and resolution
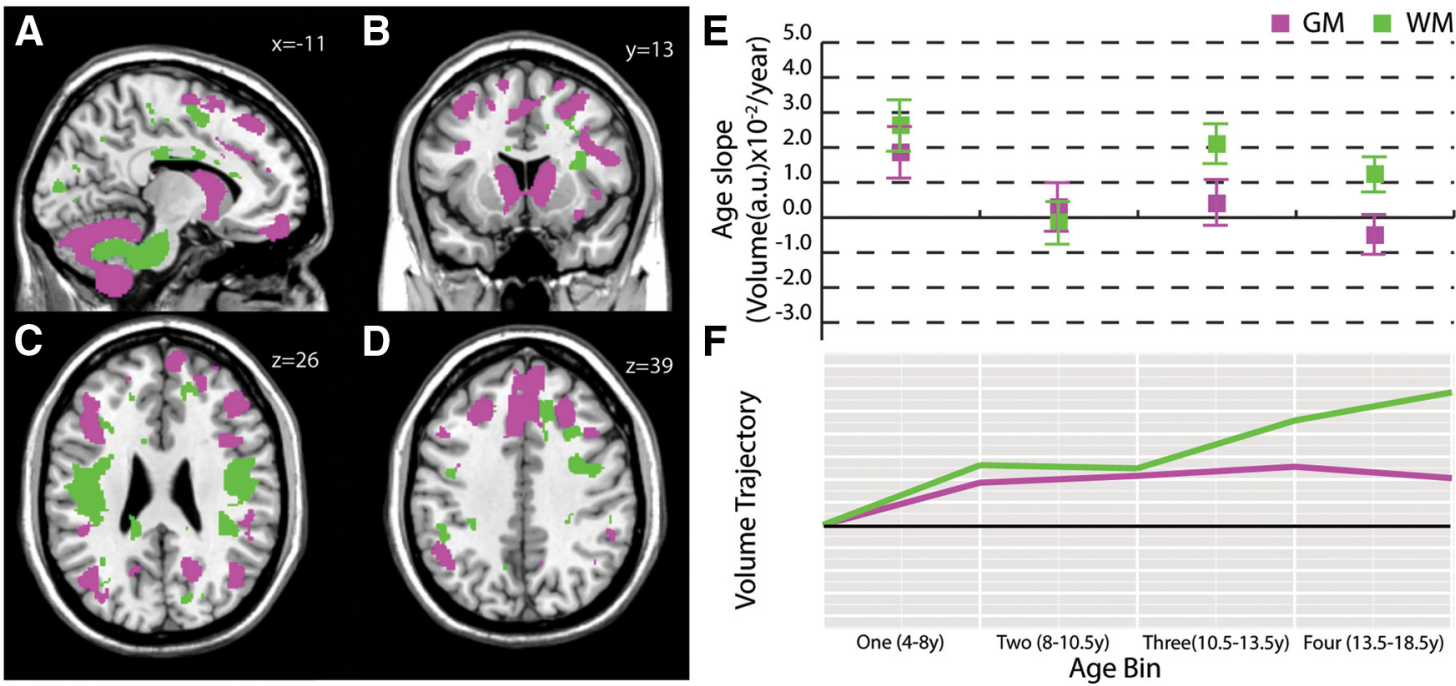

Figure 4. Cerebellar white and gray matter clusters. This white matter cluster included the cerebellum and cerebellar peduncles $(\boldsymbol{A})$, including white matter in portions of the superior longitudinal fasciculus $(\boldsymbol{C})$; voxels in this cluster were predominantly oriented anterior-posterior (58\%). The corresponding gray matter cluster included the bilateral cerebellum $(\boldsymbol{A})$, caudate $(\boldsymbol{B})$, and dorsomedial prefrontal cortex $(\boldsymbol{D})$. Mean gray and white matter slopes for the cluster with SDs $(\boldsymbol{E})$ and a graphical illustration of volume trajectories $(\boldsymbol{F})$ are shown for all four age bins. 
a
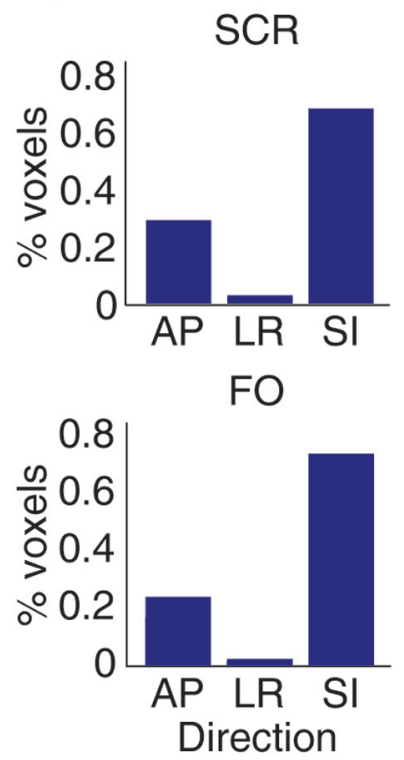

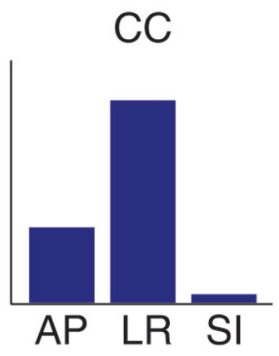

Cerebellum

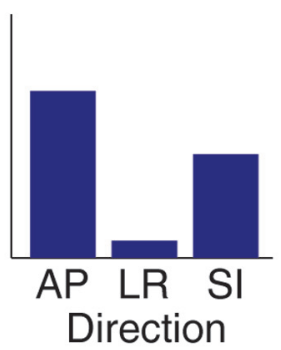

b

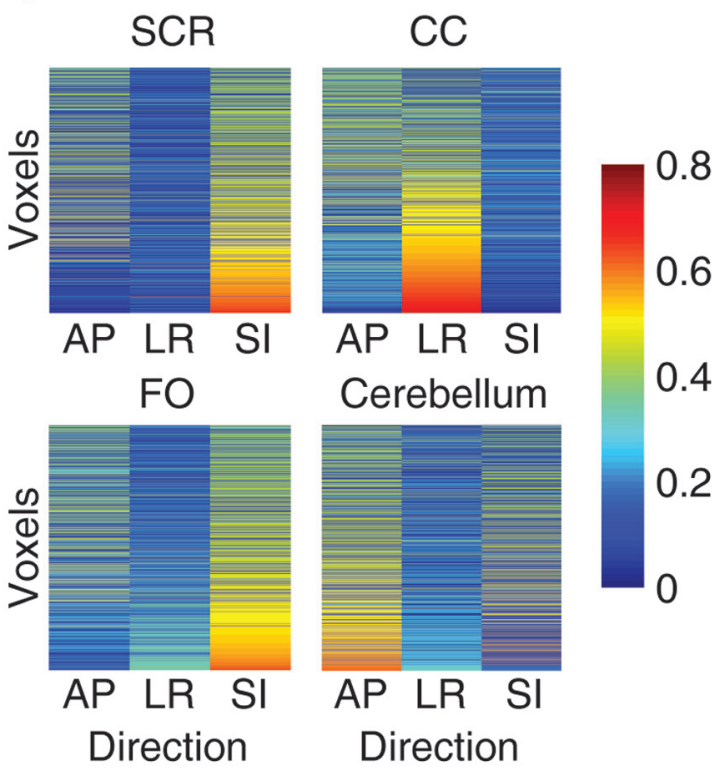

Figure 5. Preferred white matter direction in each cluster. For this analysis, the voxels within each cluster were thresholded to only those voxels with an eigenvalue $\geq 0.4$ in one of the three canonical directions. $a$, Shows the proportion of voxels for the maximum value in each direction. $\boldsymbol{b}$, Illustrates eigenvalues for all three directions across all voxels with at least one eigenvalue $\geq 0.4$, sorted by maximum value in each row (i.e., each row is one voxel; heat map indicates the eigenvalue at that voxel for each canonical direction). SCR, superior corona radiata; CC, corpus callosum; FO, fronto-occipital; AP, anterior-posterior; LR, left-right; SI, superior-inferior.

may have a fairly localized effect in subcortical regions, and we note that reliability of cluster assignment in these regions is a limitation of the present work.

\section{Effects of modeling total gray and white matter volume}

Two additional analyses were run using proportional scaling by total tissue volume and including total tissue volume as a covariate (ANCOVA). The resulting parameter estimates for age were entered into a similar cluster analysis as that described above. These analyses identified very similar clusters (Fig. 7), however, with some differences specifically in white matter clustering in the midbrain for the ANCOVA model.

\section{Effects of image contrast}

White/gray matter contrast values for each lobe (frontal, temporal, parietal, and occipital) were entered into ANOVAs modeling effect of site with age as a covariate. Models were run across the entire sample and within each age bin. This analysis showed a significant effect of site in the temporal $\left(F_{(1,357)}=16.6, p<0.001\right)$ lobe and a trend level effect in the frontal lobe $\left(F_{(1,357)}=4.3, p=0.04\right.$ uncorrected for multiple comparisons). Over the entire sample there was a trend-level, negative association with age in the parietal cortex $\left(F_{(1,357)}=3.9, p=0.048\right.$ uncorrected). However, age was not a significant predictor of contrast within any of the age bins, for any of the lobes. From these results we conclude that image contrast is unlikely to have biased age slopes in this analysis.

\section{Discussion}

In this study, white and gray matter volumes were divided into clusters based on the similarity of age-related volume changes from 4-18 years. The four identified white matter clusters each showed a dominant orientation of fibers (anterior to posterior, left to right, and two clusters superior to inferior), and could be uniquely matched to a spatially proximal gray matter volume cluster. Gray matter clusters corresponded to cerebellar, medial/anterior, and sensorimotor clusters, respectively. Within gray and white matter network pairs, slopes followed similar trajectories across ages.

To our knowledge, this study is the first to investigate the organization of age-related structural variability in white matter volumes. Our results suggest that datadriven clustering of age-related variability in white matter volume can, to some extent, recover anterior-to-posterior, left-to-right, and superior-to-inferior directional components. While previous work has shown region- and tractspecific white matter volume changes with age (Tamnes et al., 2010; Lebel and Beaulieu, 2011), our results suggest a relationship between age-related variability in white matter volume and fiber direction. We also note that the identified clusters generally did not segregate deep from superficial white matter. These findings add to our understanding of properties of white matter volume development.

Furthermore, our results demonstrate a spatial and temporal relationship between patterns of age variability in white and gray matter volume. Previous work had shown that in individuals aged 8-30 years (Tamnes et al., 2010) 
a
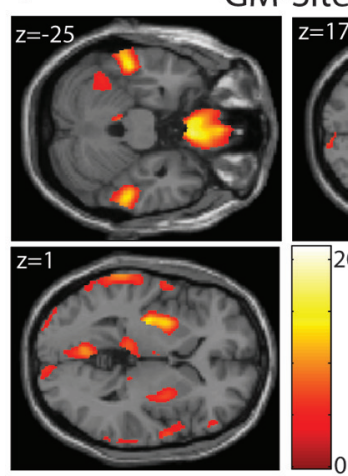

C

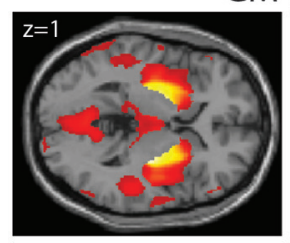

GM-Res.
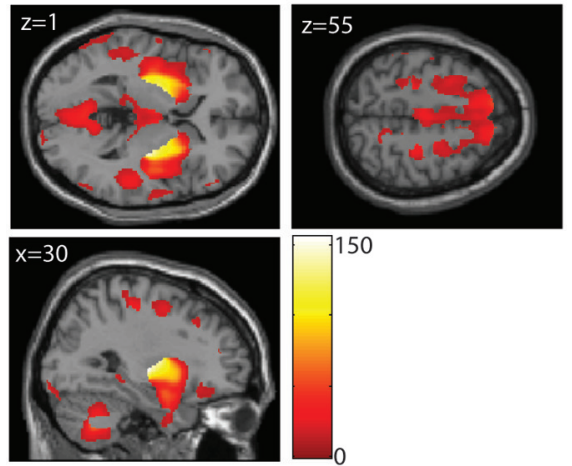

e

With Site\&Res.

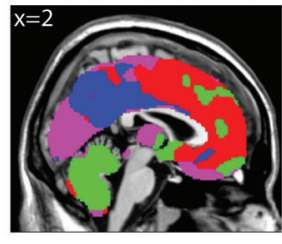

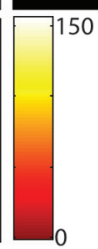

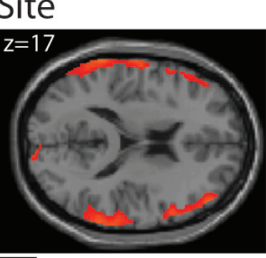

20

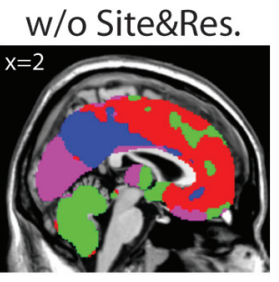

b WM-Site
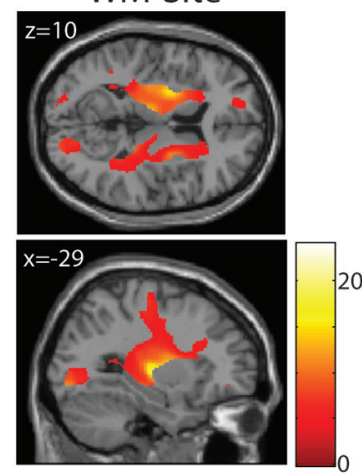

d

WM-Res.

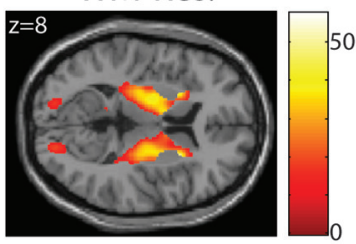

f

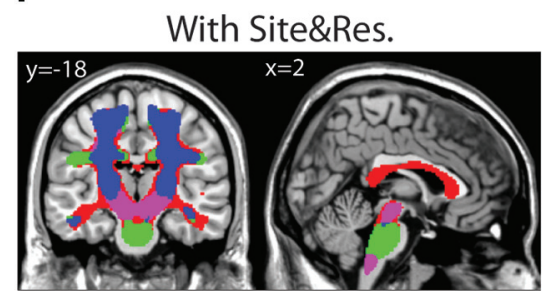

w/o Site\&Res.

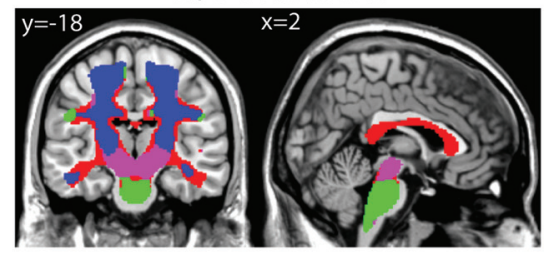

h
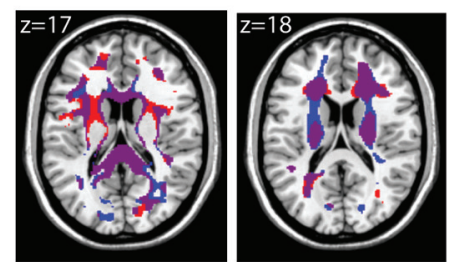

Figure 6. Effects of site and resolution on regional volume and clustering results. $\boldsymbol{a}, \boldsymbol{b}$, Results of an $F$-contrast for effects of site, thresholded at $p<0.001$ uncorrected, on gray and white matter volume, respectively. Site effects were identified around the putamen and internal capsule as well as medial orbital and peripheral gray matter. $\boldsymbol{c}, \boldsymbol{d}$, Results of an F-contrast for effects of resolution, thresholded at $p<0.001$ uncorrected, on gray and white matter volume, respectively. Effects were again concentrated around the internal capsule, with gray matter effects in dorsal prefrontal, occipital cortices, and cerebellum. $\mathbf{e}, \boldsymbol{f}$, Illustrate clustering results for age $\beta$-estimates from gray $(\boldsymbol{e})$ and white $(\boldsymbol{f})$ matter models that included effects of site and resolution (left and superior) and from 
continued

models that did not include these effects (right and inferior). We note that these are largely similar. $\boldsymbol{g}, \boldsymbol{h}$, Illustrate regions of overlap (purple) and difference (red and blue) in cluster assignment for gray $(\mathbf{g})$ and white $(\boldsymbol{h})$ matter clusters when site and resolution are taken into account. The only substantial differences in clustering results were in posterior putamen and near the internal capsule. GM, gray matter; WM, white matter.

there are negative correlations between cortical thickness and volumes of corresponding gyral white matter. Wu et al. (2014) found that the association between superficial white matter FA and cortical thickness was positive in a

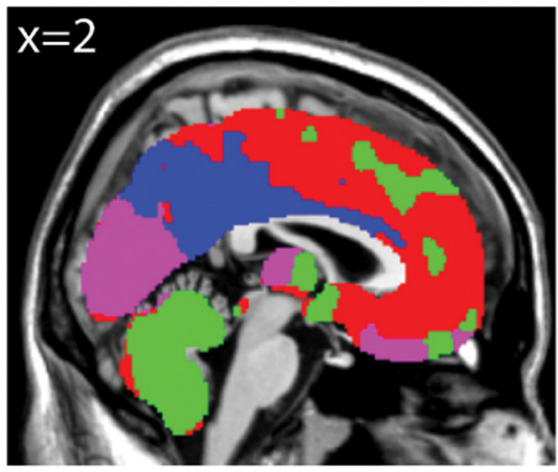

C

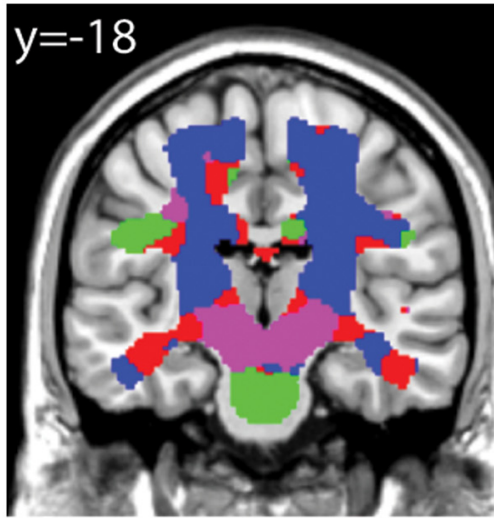

d

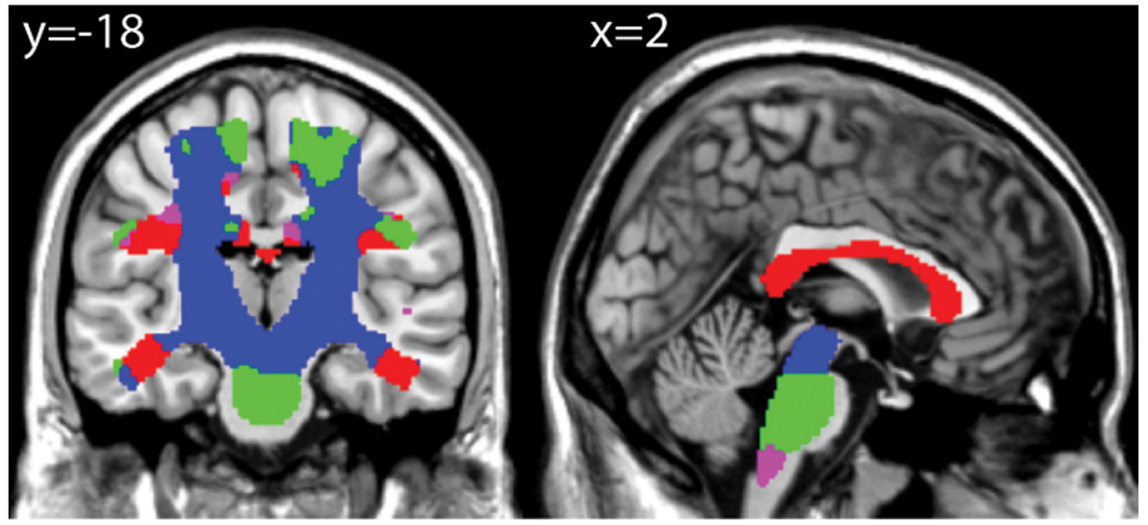

b
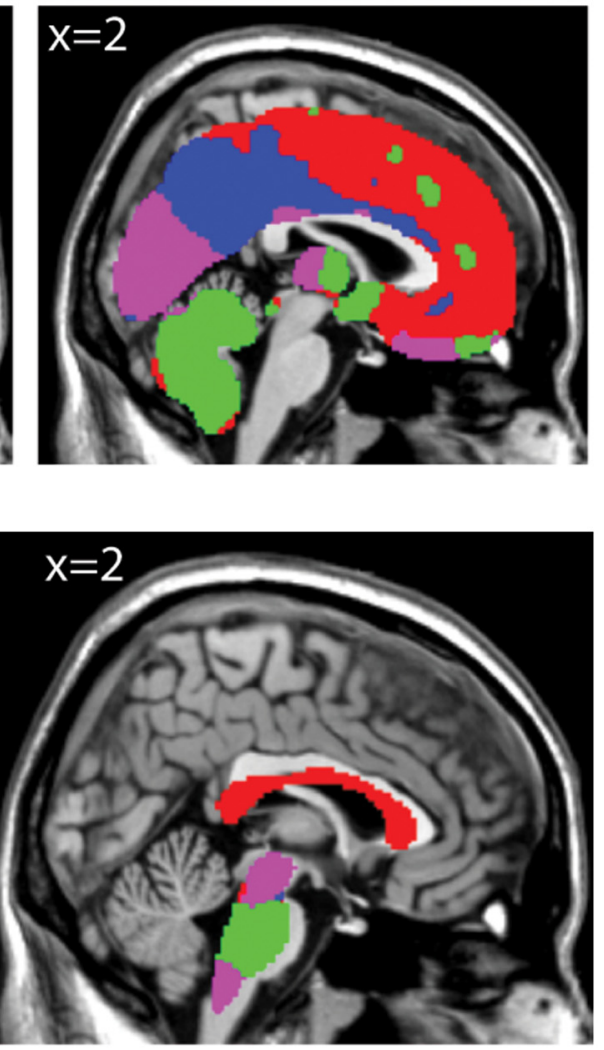$$
\text { . }
$$ 
unimodal sensory areas, but negative in polymodal regions. In adolescents, a negative correlation between gray matter density and FA in the right superior corona radiata has been described (Giorgio et al., 2008). These studies show that the general pattern of maturational contraction of gray matter is coupled with changes in white matter properties, including increased FA and volume. The present study builds on these findings by showing that there is a network organization in patterns of age-related variability in both gray and white matter volumes, and that these clusters are coupled based on both spatial proximity and similarity in age slopes.

White matter development across childhood and adolescence is characterized by increased FA and volume and reduced MD (Barnea-Goraly et al., 2005; Ben Bashat et al., 2005; Giorgio et al., 2008; Lebel and Beaulieu, 2011). These processes occur asynchronously across white matter regions (Lebel et al., 2008), and are believed to reflect changes in myelination and axonal packing (Yakovlev and Lecours, 1967; Beaulieu, 2002). White matter properties such as FA appear to be influenced by both genetic (Kochunov et al., 2015) and environmental (Hofstetter et al., 2013) factors. We speculate that genes expressed within regions or networks may contribute to coordinated patterns of volume development observed here. Though often considered separately, gray and white matter development may reflect processes occurring in the same cells (though changes in gray matter may also reflect changes in glial cells or vasculature; Zatorre et al., 2012). We further speculate that coordinated white matter expansion and gray matter contraction may reflect a synergistic process of increased myelination and decreased synaptic or dendritic density that occurs as networks mature. We note, however, that MRI studies are quite limited in resolution and thus have limited ability to test these hypotheses directly.

Different distributed networks have been identified in fMRI connectivity studies, including default-mode or tasknegative, frontoparietal/dorsal attention/task positive, ventral attention, salience, visual, motor, and subcortical networks (Fox et al., 2005; Power et al., 2011). A previous seed-based study showed that longitudinal change in cortical thickness in core regions of the task-positive and task-negative networks are correlated (Raznahan et al., $2011 b)$. We note that using a data-driven approach, the gray matter clusters identified here did not specifically resemble either of these two networks. Instead, we found a posterior cluster that included both precuneus and bilateral intraparietal sulcus, regions associated with both the task-positive and task-negative networks. An anterior cluster included both medial prefrontal task-negative regions and cingulate and dorsal prefrontal regions associated with task-positive and salience networks. A recent study using a qualitatively similar approach to that described here also identified one primarily parietal network and several networks that bisected the prefrontal cortex into superior and inferior regions (Alexander-Bloch et al., 2014). Although similarities in network properties of maturational and functional networks have been shown (Alexander-Bloch et al., 2013b), recent results (AlexanderBloch et al., 2014), together with those reported here, suggest that the spatial distribution of maturational structural covariance networks may not map directly onto canonical functional networks. Further work is required to carefully characterize the relationship between developmental gray matter networks and brain systems defined based on functional connectivity.

Our results suggest a period of particular cortical thinning in late childhood in the anterior and posterior gray matter clusters that consist of more cognitive frontal, parietal, insular, and temporal regions. This has also been noted as a period of nonlinear change in cortical thickness networks, when local efficiency is reduced but global efficiency increases (Khundrakpam et al., 2013). In terms of cognitive development, late childhood corresponds to a period of rapid maturation of attention and executive functions (Pennington and Groisser, 1991; Hommel et al., 2004; Zhan et al., 2011). Our data suggest that cortical thinning most prominently in parietal regions, but also in the more anterior cortical network, may play a role in this process. A goal for future longitudinal studies will be to consider the maturational trajectories of gray and white matter networks in relation to cognitive maturation.

There are several limitations associated with this study. We used a single time point rather than longitudinal measurements to identify age slopes. Male and female participants were included in our analysis in similar numbers, though previous studies have shown evidence for sexually dimorphic trajectories in gray and white matter development (Giedd et al., 1997; Lenroot et al., 2007; Raznahan et al., 2011a). VBM analyses do not allow for separation of volume into thickness and surface area components, which make distinct contributions to volume development (Raznahan et al., 2011a). The age windows used here were defined to correspond with recent reports (Zielinski et al., 2010; Khundrakpam et al., 2013); however, these are somewhat arbitrary divisions and may not reflect optimal boundaries for transitions in age slope. The "optimal" number of clusters as defined using silhouette values did not match for gray and white matter clusters; the gray matter solution peaked at two clusters, separating cortical from cerebellar regions, while the white matter solution peaked at four clusters. We chose to model gray matter using a four-cluster solution, to match the white optimal white matter solution, and therefore note that gray matter clusters in the cortex may reflect gradations of a

Statistical table

\begin{tabular}{llll}
\hline & Data structure & Type of test & Power \\
a & White matter volume (normally distributed) & K-means clustering, silhouette values & n/a \\
b & Gray matter volume (normally distributed) & K-means clustering, silhouette values & n/a \\
\hline
\end{tabular}

Mean, SD, and range were calculated for age and IQ in each group. Handedness reflects right (R) versus left (L) hand preference. Mean adjusted income is measured in thousands of dollars. 
largely similar age-related volume pattern rather than substantially distinct clusters. Significant effects of data acquisition site and resolution were most prominent around the internal capsule, putamen, and posterior insula; clustering results in these areas may therefore be less reliable. Finally, we note that our analysis identified a set of gray and white matter clusters that covered regions that are very different in terms of cellular composition. As such, this analysis did not perform well at identifying regions with particular properties.

In summary, this work describes a correspondence between clusters of white and gray matter regions, defined in terms of age-related variability in volume across childhood and adolescence. We found that white matter voxels clustered together based largely on fiber direction, and gray matter regions divided into anterior, posterior, sensorimotor, and cerebellar clusters. These gray and white matter clusters could, nonetheless, be uniquely matched on the basis of spatial proximity, and showed parallel trajectories in age-related variability. This study identifies a previously unreported property of directional selectivity in white matter volume development, and demonstrates that white and gray matter volume clusters are linked across childhood and adolescence. There is a growing interest in understanding the role of anatomical networks in neurodevelopmental (Zielinski et al., 2012), neuropsychiatric (Alexander-Bloch et al., 2014), and neurodegenerative (Douaud et al., 2014) disorders; these results lay a foundation for studying network-level abnormalities in white matter volume and their relationship to gray matter covariance networks.

\section{References}

Alexander-Bloch, A, Giedd JN, Bullmore E. (2013a). Imaging structural co-variance between human brain regions. Nat Rev Neurosci 14:322-336. CrossRef Medline

Alexander-Bloch A, Raznahan A, Bullmore E, Giedd J. (2013b). The convergence of maturational change and structural covariance in human cortical networks. J Neurosci 33:2889-2899. CrossRef Medline

Alexander-Bloch AF, Reiss PT, Rapoport J, McAdams H, Giedd JN, Bullmore ET, Gogtay N. (2014). Abnormal cortical growth in schizophrenia targets normative modules of synchronized development. Biol Psychiatry 76:438-446.

Ashburner J. (2007). A fast diffeomorphic image registration algorithm. Neuroimage 38:95-113. CrossRef Medline

Barnea-Goraly N, Menon V, Eckert M, Tamm L, Bammer R, Karchemskiy A, Dant CC, Reiss AL. (2005). White matter development during childhood and adolescence: a cross-sectional diffusion tensor imaging study. Cereb Cortex 15:1848-1854. CrossRef Medline

Beaulieu C. (2002). The basis of anisotropic water diffusion in the nervous system-a technical review. NMR Biomed 15:435-455. CrossRef Medline

Ben Bashat D, Ben Sira L, Graif M, Pianka P, Hendler T, Cohen Y, Assaf Y. (2005). Normal white matter development from infancy to adulthood: comparing diffusion tensor and high $b$ value diffusion weighted MR images. J Magn Reson Imaging 21:503-511. CrossRef Medline

Benes FM. (1989). Myelination of cortical-hippocampal relays during late adolescence. Schizophr Bull 15:585-593. Medline

Benes FM, Turtle M, Khan Y, Farol P. (1994). Myelination of a key relay zone in the hippocampal formation occurs in the human brain during childhood, adolescence, and adulthood. Arch Gen Psychiatry 51:477-484. Medline

Chen ZJ, He Y, Rosa-Neto P, Germann J, Evans AC. (2008). Revealing modular architecture of human brain structural networks by using cortical thickness from MRI. Cereb Cortex 18:2374-2381. CrossRef Medline

Cotter D, Mackay D, Chana G, Beasley C, Landau S, Everall IP. (2002). Reduced neuronal size and glial cell density in area 9 of the dorsolateral prefrontal cortex in subjects with major depressive disorder. Cereb Cortex 12:386-394. Medline

Douaud G, Groves AR, Tamnes CK, Westlye LT, Duff EP, Engvig A, Walhovd KB, James A, Gass A, Monsch AU, Matthews PM, Fiell AM, Smith SM, Johansen-Berg H. (2014). A common brain network links development, aging, and vulnerability to disease. Proc Natl Acad Sci USA 111:17648-17653. CrossRef Medline

Drevets WC, Ongür D, Price JL. (1998). Neuroimaging abnormalities in the subgenual prefrontal cortex: implications for the pathophysiology of familial mood disorders. Mol Psychiatry 3:220-226, 190191. Medline

Elgeti H, Elgeti R, Fleischhauer K. (1976). Postnatal growth of the dorsal lateral geniculate nucleus of the cat. Anat Embryol 149:113. Medline

Evans AC. (2013). Networks of anatomical covariance. Neuroimage 80:489-504. CrossRef Medline

Evans AC, Brain Development Cooperative Group. (2006). The NIH MRI study of normal brain development. Neuroimage 30:184-202. CrossRef Medline

Focke NK, Helms G, Kaspar S, Diederich C, Tóth V, Dechent P, Mohr A, Paulus W. (2011). Multi-site voxel-based morphometry-not quite there yet. Neuroimage 56:1164-1170. CrossRef Medline

Fox MD, Snyder AZ, Vincent JL, Corbetta M, Van Essen DC, Raichle, ME. (2005). The human brain is intrinsically organized into dynamic, anticorrelated functional networks. Proc Natl Acad Sci USA 102:9673-9678. CrossRef

Giedd JN, Castellanos FX, Rajapakse JC, Vaituzis AC, Rapoport JL. (1997). Sexual dimorphism of the developing human brain. Prog Neuropsychopharmacol Biol Psychiatry 21:1185-1201. Medline

Giedd JN, Blumenthal J, Jeffries NO, Castellanos FX, Liu H, Zijdenbos A, Paus T, Evans AC, Rapoport JL. (1999). Brain development during childhood and adolescence: a longitudinal MRI study. Nat Neurosci 2:861-863. CrossRef Medline

Giorgio A, Watkins KE, Douaud G, James AC, James S, De Stefano N, Matthews PM, Smith SM. (2008). Changes in white matter microstructure during adolescence. Neuroimage 39:52-61. CrossRef Medline

Gogtay N, Giedd JN, Lusk L, Hayashi KM, Greenstein D, Vaituzis AC, Nugent TF 3rd, Herman DH, Clasen LS, Toga AW, Rapoport JL, Thompson PM. (2004). Dynamic mapping of human cortical development during childhood through early adulthood. Proc Natl Acad Sci USA 101:8174-8179. CrossRef Medline

Gong G, He Y, Chen ZJ, Evans, AC. (2012). Convergence and divergence of thickness correlations with diffusion connections across the human cerebral cortex. Neuroimage 59:1239-1248. CrossRef Medline

Hofstetter S, Tavor I, Tzur Moryosef S, Assaf Y. (2013). Short-term learning induces white matter plasticity in the fornix. J Neurosci 33:12844-12850. CrossRef Medline

Hommel B, Li KZ, Li SC. (2004). Visual search across the life span. Dev Psychol 40:545-558. CrossRef Medline

Huttenlocher PR. (1979). Synaptic density in human frontal cortexdevelopmental changes and effects of aging. Brain Res 163:195205. Medline

Innocenti GM, Price DJ. (2005). Exuberance in the development of cortical networks. Nat Rev Neurosci 6:955-965. CrossRef Medline

Kaufman L, Rousseeuw PJ. (1990). Finding groups in data: an introduction to cluster analysis. Hoboken, NJ: John Wiley.

Khundrakpam BS, Reid A, Brauer J, Carbonell F, Lewis J, Ameis S, Karama S, Lee J, Chen Z, Das S, Evans AC, Brain Development Cooperative Group. (2013). Developmental changes in organiza- 
tion of structural brain networks. Cereb Cortex 23:2072-2085. CrossRef Medline

Kochunov P, Jahanshad N, Marcus D, Winkler A, Sprooten E, Nichols TE, Wright SN, Hong LE, Patel B, Behrens T, Jbabdi S, Andersson J, Lenglet C, Yacoub E, Moeller S, Auerbach E, Uqurbil K, Sotiropoulos SN, Brouwer RM, Landman B, et al. (2015). Heritability of fractional anisotropy in human white matter: a comparison of Human Connectome Project and ENIGMA-DTI data. Neuroimage 111:300-311. CrossRef Medline

Lebel C, Beaulieu C. (2011). Longitudinal development of human brain wiring continues from childhood into adulthood. J Neurosci 31:10937-10947. CrossRef Medline

Lebel C, Walker L, Leemans A, Phillips L, Beaulieu C. (2008). Microstructural maturation of the human brain from childhood to adulthood. Neuroimage 40:1044-1055. CrossRef Medline

Lebel C, Gee M, Camicioli R, Wieler M, Martin W, Beaulieu C. (2012). Diffusion tensor imaging of white matter tract evolution over the lifespan. Neuroimage 60:340-352. CrossRef Medline

Lenroot RK, Gogtay N, Greenstein DK, Wells EM, Wallace GL, Clasen LS, Blumenthal JD, Lerch J, Zijdenbos AP, Evans AC, Thompson PM, Giedd JN. (2007). Sexual dimorphism of brain developmental trajectories during childhood and adolescence. Neuroimage 36: 1065-1073. CrossRef Medline

Lerch JP, Worsley K, Shaw WP, Greenstein DK, Lenroot RK, Giedd J, Evans AC. (2006). Mapping anatomical correlations across cerebral cortex (MACACC) using cortical thickness from MRI. Neuroimage 31:993-1003. CrossRef Medline

Maldjian JA, Laurienti PJ, Kraft RA, Burdette JH. (2003). An automated method for neuroanatomic and cytoarchitectonic atlasbased interrogation of fMRI data sets. Neuroimage 19:1233-1239. Medline

Mazziotta J, Toga A, Evans A, Fox P, Lancaster J, Zilles K, Woods, R., Paus T, Simpson G, Pike B, Holmes C, Collins L, Thompson P, MacDonald D, lacoboni M, Schormann T, Amunts K, PalomeroGallagher N, Geyer S, Parsons L, et al. (2001). A four-dimensional probabilistic atlas of the human brain. J Am Med Inform Assoc 8:401-430. Medline

Mechelli A, Friston KJ, Frackowiak RS, Price CJ. (2005). Structural covariance in the human cortex. J Neurosci 25:8303-8310. CrossRef Medline

Mori S, Oishi K, Jiang H, Jiang L, Li X, Akhter K, Hua K, Faria AV, Mahmood A, Woods R, Toga AW, Pike GB, Neto PR, Evans A, Zhang J, Huang H, Miller MI, van Zijl P, Mazziotta J. (2008). Stereotaxic white matter atlas based on diffusion tensor imaging in an ICBM template. Neuroimage 40:570-582. CrossRef Medline

Oishi K, Faria A, van Zijl P, Mori S. (2011). MRI atlas of human white matter. Amsterdam: Elsevier.

Pardoe H, Pell GS, Abbott DF, Berg AT, Jackson GD. (2008). Multisite voxel-based morphometry: methods and a feasibility demonstration with childhood absence epilepsy. Neuroimage 42:611616. CrossRef Medline

Paus T. (2010). Growth of white matter in the adolescent brain: myelin or axon?. Brain Cogn 72:26-35. CrossRef Medline

Paus T, Zijdenbos A, Worsley K, Collins DL, Blumenthal J, Giedd JN, Rapoport JL, Evans AC. (1999). Structural maturation of neural pathways in children and adolescents: in vivo study. Science 283:1908-1911. Medline

Paus T, Collins DL, Evans AC, Leonard G, Pike B, Zijdenbos A. (2001). Maturation of white matter in the human brain: a review of magnetic resonance studies. Brain Res Bull 54:255-266. Medline

Peelle JE, Cusack R, Henson RN. (2012). Adjusting for global effects in voxel-based morphometry: gray matter decline in normal aging. Neuroimage 60:1503-1516. CrossRef Medline

Pennington BF, Groisser DB. (1991). A normative-developmental study of executive function: A window on prefrontal function in children. Dev Neuropsychol 7:131-149. CrossRef

Pereira JM, Nestor PJ, Williams GB. (2008). Impact of inconsistent resolution on VBM studies. Neuroimage 40:711-717. CrossRef Medline
Power JD, Cohen AL, Nelson SM, Wig GS, Barnes KA, Church JA, Vogel AC, Laumann TO, Miezin FM, Schlaggar BL, Petersen SE. (2011). Functional network organization of the human brain. Neuron 72:665-678. CrossRef Medline

Rademacher J, Engelbrecht V, Bürgel U, Freund H, Zilles K. (1999). Measuring in vivo myelination of human white matter fiber tracts with magnetization transfer MR. Neuroimage 9:393-406. Medline

Raznahan A, Cutter W, Lalonde F, Robertson D, Daly E, Conway GS, Skuse DH, Ross J, Lerch JP, Giedd JN, Murphy DD. (2010). Cortical anatomy in human X monosomy. Neuroimage 49:29152923. CrossRef Medline

Raznahan A, Shaw P, Lalonde F, Stockman M, Wallace GL, Greenstein D, Clasen L, Gogtay N, Giedd JN. (2011a). How does your cortex grow?. J Neurosci 31:7174-7177. CrossRef Medline

Raznahan A, Lerch JP, Lee N, Greenstein D, Wallace GL, Stockman M, Clasen L, Shaw PW, Giedd JN. (2011b). Patterns of coordinated anatomical change in human cortical development: a longitudinal neuroimaging study of maturational coupling. Neuron 72 : 873-884. CrossRef Medline

Reid AT, van Norden AG, de Laat KF, van Oudheusden LJ, Zwiers MP, Evans AC, de Leeuw FE, Kötter R. (2010). Patterns of cortical degeneration in an elderly cohort with cerebral small vessel disease. Hum Brain Mapp 31:1983-1992. CrossRef Medline

Ridgway GR, Omar R, Ourselin S, Hill DL, Warren JD, Fox NC (2009). Issues with threshold masking in voxel-based morphometry of atrophied brains. Neuroimage 44:99-111. CrossRef Medline

Seeley WW, Crawford RK, Zhou J, Miller BL, Greicius MD. (2009). Neurodegenerative diseases target large-scale human brain networks. Neuron 62:42-52. CrossRef Medline

Segall JM, Allen EA, Jung RE, Erhardt EB, Arja SK, Kiehl K, Calhoun VD. (2012). Correspondence between structure and function in the human brain at rest. Front Neuroinform 6:10. CrossRef Medline

Shaw P, Kabani NJ, Lerch JP, Eckstrand K, Lenroot R, Gogtay N, Greenstein D, Clasen L, Evans A, Rapoport JL, Giedd JN, Wise SP. (2008). Neurodevelopmental trajectories of the human cerebral cortex. J. Neurosci 28:3586-394. CrossRef Medline

Shi F, Fan Y, Tang S, Gilmore JH, Lin W, Shen D. (2010). Neonatal brain image segmentation in longitudinal MRI studies. Neuroimage 49:391-400. CrossRef Medline

Sowell ER, Trauner DA, Gamst A, Jernigan TL. (2002). Development of cortical and subcortical brain structures in childhood and adolescence: a structural MRI study. Dev Med Child Neurol 44:4-16. Medline

Sowell ER, Peterson BS, Thompson PM, Welcome SE, Henkenius AL, Toga AW. (2003). Mapping cortical change across the human life span. Nat Neurosci 6:309-315. CrossRef Medline

Sowell ER, Thompson PM, Leonard CM, Welcome SE, Kan E, Toga AW. (2004). Longitudinal mapping of cortical thickness and brain growth in normal children. J Neurosci 24:8223-8231. CrossRef Medline

Takao H, Hayashi N, Ohtomo K. (2013). Effects of the use of multiple scanners and of scanner upgrade in longitudinal voxel-based morphometry studies. J Magn Reson Imaging 38:1283-1291. CrossRef Medline

Taki Y, Thyreau B, Hashizume H, Sassa Y, Takeuchi H, Wu K, Kotozaki Y, Nouchi R, Asano M, Asano K, Fukuda H, Kawashima R. (2013). Linear and curvilinear correlations of brain white matter volume, fractional anisotropy, and mean diffusivity with age using voxel-based and region-of-interest analyses in 246 healthy children. Hum Brain Mapp 34:1842-1856. CrossRef

Tamnes CK, Ostby Y, Fjell AM, Westlye LT, Due-Tønnessen P, Walhovd KB. (2010). Brain maturation in adolescence and young adulthood: regional age-related changes in cortical thickness and white matter volume and microstructure. Cereb Cortex 20:534548. CrossRef Medline

Tijms BM, Seriès P, Willshaw DJ, Lawrie SM. (2012). Similarity-based extraction of individual networks from gray matter MRI scans. Cereb Cortex 22:1530-1541. CrossRef Medline 
Tzourio-Mazoyer N, Landeau B, Papathanassiou D, Crivello F, Etard O, Delcroix N, Mazoyer B, Joliot M. (2002). Automated anatomical labeling of activations in SPM using a macroscopic anatomical parcellation of the MNI MRI single-subject brain. Neuroimage 15:273-289. CrossRef Medline

Vaidya JG, Paradiso S, Boles Ponto LL, McCormick LM, Robinson RG. (2007). Aging, grey matter, and blood flow in the anterior cingulate cortex. Neuroimage 37:1346-1353. CrossRef Medline

Wu M, Lu LH, Lowes A, Yang S, Passarotti AM, Zhou XJ, Pavuluri MN. (2014). Development of superficial white matter and its structural interplay with cortical gray matter in children and adolescents. Hum Brain Mapp 35:2806-2816. CrossRef Medline

Yakovlev P, Lecours A. (1967). The myelogenetic cycles of regional maturation of the brain. In: Regional development of the brain in early life (Minkowski A, ed), pp 3-70. Boston, MA: Blackwell Scientific.
Zatorre RJ, Fields RD, Johansen-Berg H. (2012). Plasticity in gray and white: neuroimaging changes in brain structure during learning. Nat Neurosci 15:528-536. CrossRef Medline

Zhan JY, Wilding J, Cornish K, Shao J, Xie CH, Wang YX, Lee K, Karmiloff-Smith A, Zhao ZY. (2011). Charting the developmental trajectories of attention and executive function in Chinese schoolaged children. Child Neuropsychol 17:82-95. CrossRef Medline

Zielinski BA, Gennatas ED, Zhou J, Seeley WW. (2010). Networklevel structural covariance in the developing brain. Proc Natl Acad Sci USA 107:18191-18196. CrossRef Medline

Zielinski BA, Anderson JS, Froehlich AL, Prigge MB, Nielsen JA, Cooperrider JR, Cariello AN, Fletcher PT, Alexander AL, Lange N, Bigler ED, Lainhart JE. (2012). scMRI reveals large-scale brain network abnormalities in autism. PLoS One 7:e49172. CrossRef Medline 